\title{
Molecular basis of permethrin and DDT resistance in an Anopheles funestus population from Benin
}

\author{
Genevieve Tchigossou ${ }^{1,2^{*}}$, Rousseau Djouaka ${ }^{1 \dagger}$, Romaric Akoton ${ }^{1,2}$, Jacob M Riveron ${ }^{3,5}$, Helen Irving ${ }^{3}$,
} Seun Atoyebi ${ }^{4}$, Kabirou Moutairou ${ }^{2}$, Akadiri Yessoufou ${ }^{2}$ and Charles S Wondji, ${ }^{3,5}$

\begin{abstract}
Background: Insecticide resistance in Anopheles mosquitoes is threatening the success of malaria control programmes. In order to implement suitable insecticide resistance management strategies, it is necessary to understand the underlying mechanisms involved. To achieve this, the molecular basis of permethrin and DDT resistance in the principal malaria vector, Anopheles funestus from inland Benin (Kpome), was investigated.

Results: Here, using a microarray-based genome-wide transcription and GRT-PCR analysis, we showed that metabolic resistance mechanisms through over-expression of cytochrome P450 and glutathione S-transferase genes (GSTs) are a major contributor to DDT and permethrin resistance in Anopheles funestus from Kpome. The GSTe2 gene was the most upregulated detoxification gene in both DDT- [fold-change (FC: 16.0)] and permethrin-resistant (FC: 18.1) mosquitoes suggesting that upregulation of this gene could contribute to DDT resistance and cross-resistance to permethrin. CYP6P9a and CYP6P96 genes that have been previously associated with pyrethroid resistance were also significantly overexpressed with FC 5.4 and 4.8, respectively, in a permethrin resistant population. Noticeably, the GSTs, GSTd1-5 and GSTd3, were more upregulated in DDT-resistant than in permethrinresistant Anopheles funestus suggesting these genes are more implicated in DDT resistance. The absence of the L1014F or L1014S kdr mutations in the voltage-gated sodium channel gene coupled with the lack of directional selection at the gene further supported that knockdown resistance plays little role in this resistance.

Conclusions: The major role played by metabolic resistance to pyrethroids in this An. funestus population in Benin suggests that using novel control tools combining the P450 synergist piperonyl butoxide (PBO), such as PBO-based bednets, could help manage the growing pyrethroid resistance in this malaria vector in Benin.
\end{abstract}

Keywords: Anopheles funestus, Insecticide resistance, Permethrin, DDT, Kpome, Resistance mechanisms

\section{Background}

There were an estimated 216 million cases of malaria worldwide in 2016 and 445,000 deaths with $80 \%$ of all malaria deaths occurring in Africa [1]. Despite extensive control efforts, over half the world's population remains at risk and the disease has a massive impact on health and economic development, particularly in Africa [2]. Four species of Anopheles, An. gambiae Giles, An.

\footnotetext{
* Correspondence: tchigossougenevieve@yahoo.fr

${ }^{\dagger}$ Genevieve Tchigossou and Rousseau Djouaka contributed equally to this work.

'International Institute of Tropical Agriculture, Cotonou 08 BP 0932, Benin

2University of Abomey Calavi, BP 526 Cotonou, Benin

Full list of author information is available at the end of the article
}

coluzzii Coetzee \& Wilkerson, An. arabiensis Patton and An. funestus Giles, are responsible for most of the malaria transmission in this continent. The transmission role of An. funestus (sensu stricto) is further supported by observations that in many regions of Africa, its infection rate even surpasses that of An. gambiae [3]. Long-lasting insecticidal nets (LLINs) and indoor residual spraying (IRS) are the main malaria prevention interventions [4]. However, the success of these control methods is jeopardised by the development of resistance by Anopheles species to insecticides such as pyrethroids and DDT as seen in the past with loss of efficacy of dieldrin for IRS in west/central Africa [5, 6]. In Benin, due

(c) The Author(s). 2018 Open Access This article is distributed under the terms of the Creative Commons Attribution 4.0 International License (http://creativecommons.org/licenses/by/4.0/), which permits unrestricted use, distribution, and 
to vector resistance to pyrethroids across the country [710], two insecticides of two different classes were used in rotation for IRS: bendiocarb (a carbamate) and pirimiphos-methyl (an organophosphate) [11]. However, DDT is still retained for use in IRS, due to the limited number of cost-effective alternatives [12]. Field studies on insecticide susceptibility carried out as baseline surveys for malaria control programs showed An. funestus to be resistant to various insecticides at various localities $[9,10$, 13]. Metabolic resistance is the main resistance mechanism recorded, and cytochrome P450 genes are playing a major role while target-site resistance like the knockdown resistance $(\mathrm{kdr})$ is absent $[9,14-17]$. Target site resistance was investigated in the pyrethroid/DDT-resistant population and the fifth and sixth segments of domain II in the sodium channel sequence and no polymorphism associated with resistance was identified $[9,14,16,18-20]$ although some mutations have been detected in Cameroon [21] and Uganda [22] but with no association yet established with resistance phenotype. A significant increase in mono-oxygenase activities confers resistance to pyrethroids in An. funestus in Mozambique and South-Africa (southern Africa) [15, 23-25], Uganda (east Africa) [16, 22, 26], western Kenya (east Africa) [18, 22], Cameroon (central Africa) [21] and in Senegal (west Africa) [19]. Characterisation of the molecular basis of resistance to pyrethroids and DDT in An. funestus from the coastal area of Benin [27] revealed a predominant role played by the glutathione S-transferase GSTe2. The enzyme encoded by this gene was highly upregulated in association with the presence of an L119F mutation in the substrate binding site conferring a high level of DDT and permethrin resistance [27]. Recently, An. funestus from Kpome, an inland region of Benin has also been shown to be resistant to DDT and permethrin with mortality rates of $9.1 \pm 2.5 \%$ and $13.0 \pm 3 \%$, respectively [10]. However, it remains unknown if the resistant mechanism is the same as observed in Pahou, the coastal area of Benin [9] or whether different resistance mechanisms are responsible for the spread of resistance across the country. Such information is essential in designing suitable control interventions nationwide and to improve the implementation of resistance management strategies against An. funestus. In this study, using a genome-wide microarray-based transcription analysis, the underlying molecular mechanisms conferring DDT and permethrin resistance in Kpome were characterised revealing that both glutathione S-transferases, notably the GSTe2, and cytochrome P450 genes are the main drivers of resistance.

\section{Methods}

\section{Area of study and mosquito collection}

Blood-fed adult female An. funestus mosquitoes resting indoors were collected in houses between 06:00 and
10:00 h from the rural area of Kpome $\left(6^{\circ} 23^{\prime} \mathrm{N}, 2^{\circ} 13^{\prime} \mathrm{E}\right)$ a southern inland region of Benin from December 2013 to February 2014. Kpome is a large agricultural setting with the intensive production of tomatoes which mainly serve a commercial purpose and insecticides, mainly pyrethroids (deltamethrin and lambda-cyalothrin), used in public health are also used to protect tomatoes against pest attacks. Mosquito collections and rearing were performed as described previously [10]. Adult female mosquitoes were collected indoor between 06:00 to 10:00 h using electric aspirators. F1 adults were generated from field-collected female mosquitoes using the forced-egg laying method [16] and were randomly mixed in cages for subsequent experiments. All females used for individual oviposition were morphologically and molecularly identified as An. funestus (s.s.) [10, 28].

\section{Insecticide susceptibility assays}

Two to five day-old F1 adult female mosquitoes pooled from different F0 mosquitoes collected from Kpome were used for this test. Twenty to twenty-five mosquitoes per tube with at least four replicates were exposed to DDT (4\%) and permethrin $(0.75 \%)$ for $1 \mathrm{~h}$ before transferring into clean holding tube with $10 \%$ sugar solution. Final mortality was scored $24 \mathrm{~h}$ post-exposure. Survivors and dead mosquitoes were conserved for further analysis. In this study, we used the same mosquitoes from the previously published research results [10] to further describe the molecular basis of the observed resistance in this malaria vector population. Mosquito samples generated from the previous investigation were used for genetic analysis in this work. The susceptible strain used in this study has the same age as the exposed mosquitoes.

\section{Microarrays}

A genome-wide transcription profiling was performed to detect the sets of genes differentially expressed in relation to observed resistance phenotypes in An. funestus populations from Kpome. The microarray hybridisation for An. funestus was carried out using the $8 \times 60 \mathrm{k}(60$ mer) Agilent An. funestus chip. This Agilent microarray chip was designed using the eArray program (Agilent, Santa Clara, CA, US ) (A-MEXP-2374) by adding the 15,527 expressed sequence tags (ESTs) generated from another transcriptome sequencing of An. funestus [29] to the previous $4 \times 44 \mathrm{k}$ array (A-MEXP-2245) [24]. Each array was designed using 8540 ESTs generated from $A n$. funestus transcriptome 454 sequencing [30], 2850 An. funestus cDNAs from GenBank and a set of P450 genes from the $r p 1$ and $r p 2$ QTL BAC sequence [31, 32], and the 13,000 transcripts of the complete $A n$. gambiae genome. Moreover, An. gambiae detoxification genes previously present on the An. gambiae detox chip 
[33] were added to this. RNA was extracted from three batches of 10 An. funestus females (2-5 days-old) from the following sample sets: alive after exposure to $0.75 \%$ permethrin (Resistant permethrin: $\mathrm{R}_{\text {perm }}$ ) and 4\% DDT (Resistant DDT: $\mathrm{R}_{\mathrm{DDT}}$ ), un-exposed to insecticides (Control: C), and from the fully susceptible laboratory strain FANG (Susceptible: S) [a strain originating from Calueque in southern Angola in 2002 which is completely susceptible to insecticides (Hunt et al. [34]) using the Picopure RNA Isolation Kit (Arcturus, Waltham, MA, USA). The FANG colony was kept in insectary conditions (temperature of $25-28{ }^{\circ} \mathrm{C}$ with a relative humidity of $80 \%$ ) at the Liverpool School of Tropical Medicine where assays were performed. RNA quantity and quality were assessed using a NanoDrop ND1000 spectrophotometer (Thermo Fisher Scientific, Waltham, MA, USA) and Bioanalyzer (Agilent, Santa Clara, CA, USA), respectively. Each RNA sample was used to generate complementary RNA (cRNA) using the Agilent Quick Amp Labeling Kit (two-colour) following the manufacturer's protocol. cRNAs from the resistant samples (R) were labelled with a cy5 dye, and cRNAs from the susceptible strain FANG (S) were labelled with the cy3 dye. cRNA quantity and quality were assessed using the NanoDrop and Bioanalyzer before labelling. Labelled cRNAs were hybridised to the arrays for $17 \mathrm{~h}$ at $65{ }^{\circ} \mathrm{C}$ according to the manufacturer's protocol. Five hybridisations were performed for each comparison including two dyes swap per comparison. Microarray data were analysed using Genespring GX 13.0 software purchased from Agilent (Agilent). A normalisation of the data was performed with the GeneSpring feature extraction program using the lowess normalisation approach. To identify differentially expressed genes, a cut-off of 2-fold-change (FC) and a statistical significance of $P \leq 0.05$ with Benjamini-Hochberg correction for multiple testing and Storey with bootstrapping (with a cut-off of 1.5-fold-change for the R-C comparison) were applied. A false discovery analysis was also performed using the Benjamini-Hochberg correction test for multiple testing as implemented in GeneSpring.

\section{Quantitative reverse transcriptase PCR}

A qRT-PCR was used to validate the microarrays results for seven of some upregulated detoxification genes. These genes include three cytochromes P450s (CYP6M7, CYP6P9a, CYP9K1), two glutathione transferases (GSTd1-5, GSTe2), and one aldehyde oxidase (Ald oxi). Also, the expression level of CYP6P9b previously found to be strongly associated with pyrethroid resistance [19, 31, 35] and GSTd1-3, a gene shown as possibly associated with pyrethroid resistance by 454 transcriptome profiling $[19,30]$ were analysed (Table 1). One microgram of the three biological replicates for resistant (permethrin: $\mathrm{R}_{\text {perm }}$ and DDT: $\mathrm{R}_{\mathrm{DDT}}$ ), control $(\mathrm{C})$, and FANG (S) was used for cDNA synthesis using Superscript III (Invitrogen, Carlsbad, CA, USA) with oligodT20 and RNase $\mathrm{H}$ according to the manufacturer's instructions. Standard curves were established for each gene using serial dilution of cDNA. qRT-PCR amplification was performed using the MX 3005P (Agilent) system. The relative expression level and fold change (FC) of each target gene in resistant and control samples relative to susceptible were calculated according to the $2-\Delta \Delta C T$ method incorporating the PCR efficiency [36] after normalisation with the housekeeping genes ribosomal protein S7 (RSP7; AFUN007153-RA), and actin (Act5C; AFUN006819).

\section{Investigation of the role of the knockdown resistance mutation in DDT and permethrin resistance}

A fragment spanning a portion of the voltage-gated sodium channel gene (VGSC), including the 1014 codon (a portion of intron 19 and the entire exon 20, domain II, segment 6 of the VGSC gene) associated with resistance in An. gambiae, was amplified in eleven field-collected females of An. funestus from Kpome using the Exon 19F/KdrFunR2 primers (Exon 19F: 5'-TTT TTA AGC TCG CTA AAT CGT G-3'; KdrFunR2: 5'-CCG AAA TTT GAC AAA AGC AAA-3') [9, 15, 22]. The PCR products were purified using the QIAquick Purification Kit (Qiagen, Hilden, Germany) and directly sequenced. The polymorphic positions were detected through manual analysis of sequence traces using BioEdit. Sequences were aligned using ClustalW [37], and haplotype reconstruction and analysis were done using DnaSP v5.10 [38]. Kpome sequences were also compared to those previously obtained from Pahou in coastal Benin [9] and Gounougou in North Cameroon [21]. After the selection of the best model, a maximum likelihood phylogenetic tree was generated for the VGSC haplotypes in the different populations using Mega 6.06 [39]. The level of Kst of pairwise genetic differentiation between the populations was estimated in Dnasp v5.10, and the neighbour-Joining tree was built using Mega 6.06.

\section{Results}

\section{Genome-wide microarray-based transcriptional profiling} of permethrin resistance

A set of transcripts were differentially expressed ( $\geq 2$-fold change, $P \leq 0.05)$ between permethrin resistant $\left(\mathrm{R}_{\text {perm }}\right)$, susceptible (S) and control (C) mosquitoes (Fig. 1) from microarray analysis. Overall, 3669 transcripts were differentially expressed when permethrin resistant mosquitoes were compared to susceptible strains (1460 overexpressed and 2209 underexpressed), 3617 between C-S (1211 overexpressed and 2406 underexpressed) and 210 for $\mathrm{R}_{\text {perm }}-\mathrm{C}$ (91 overexpressed and 119 underexpressed). Overall, a 
Table 1 List of primers used for qRT-PCR

\begin{tabular}{llll}
\hline Primers & Forward & Reverse & Expected size (bp) \\
\hline CYP6M7 & CCAGATACTGAAAGAGAGCCTTCG & CAAGCACTGTCTTCGTACCG & 102 \\
CYP6P9a & CAGCGCGTACACCAGATTGTGTAA & TCACAATTTTCCACCTTCAAGTAATTACCCGC & 92 \\
CYP6P9b & CAGCGCGTACACCAGATTGTGTAA & TACACCTTTTCTACCTTCAAGTAATACCCGC & 97 \\
GSTe2 & GTTGAAGCAGTTGCCATACTACGAGG & TCAAGCTTAGCATTTCCTCCTITTGGC & 101 \\
GSTd3 & CACGGCCAGTCCTCTTTAG & AAGCTTCTTCGCCACCAGTA & 128 \\
GSTd1-5 & TGGAGAAATACGGCAAGGAC & CTTGGCGAAGATTTGTGGAT & 140 \\
Aldehyde oxidase & GCTCTGAACATTGCACCTCA & TGGTGTCGAACGATTGTGT & 109 \\
CYP9K1 & AGGGCTTCTGGATACGGTTC & CGTACGGTTCGGTTTGATT & 103 \\
RSP7 & GTGTTCGTTCCAAGGTGAT & TCCGAGTTCATTTCCAGCTC & 98 \\
Actin & TAAACCCAAAAGCCAATCG & ACCGGATGCATACAGTGACA & 111 \\
\hline
\end{tabular}

total of 40 transcripts were differentially expressed in all the three comparisons.

\section{Genes commonly overexpressed in $\mathrm{R}_{\text {perm }}-\mathrm{S}$, C-S and} $\mathbf{R}_{\text {perm }}-\mathbf{C}$ comparisons

Only the transcript, AGAP011496-PA (Anopheles gambiae str. PEST) was upregulated in $\mathrm{R}_{\text {perm }}-\mathrm{S}, \mathrm{R}_{\text {perm }}-\mathrm{C}$ and C-S comparisons with FC of 2.7, 1.5 and 2.3, respectively. No detoxification gene was found in the comparison of the three groups of mosquitoes.

\section{Genes commonly overexpressed in $\mathrm{R}_{\text {perm }}-\mathrm{S}$ and C-S comparisons}

Several detoxification genes were commonly overexpressed in the $\mathrm{R}_{\text {perm }}-\mathrm{S}$ and C-S. Among these genes, the transcripts for glycogenin (Afun000500) and CYP6M7, belonging to the cytochrome $\mathrm{P} 450$ gene family, were the most commonly overexpressed detoxification gene in $\mathrm{R}_{\text {perm }} \mathrm{S}$ (FC of 36.2 for Afun000500 and 34.6 for CYP6M7) and C-S (FC of 38.1 for Afun000500 and 28.9 for $C Y P 6 M 7)$. A transcript from $C Y P 6 A A 1$ was also commonly upregulated in the $\mathrm{R}_{\text {perm }}-\mathrm{S}$ and C-S samples with FC of 5.2 and 3.8, respectively. This gene is the ortholog of CYP6AA3 in An. minimus, which was shown to metabolise pyrethroids [40]. Other upregulated detoxification genes identified in $\mathrm{R}_{\text {perm }}-\mathrm{S}$ and $\mathrm{C}-\mathrm{S}$ comparisons include $C Y P 6 Y 2$ located in the genomic region spanning the pyrethroid resistance $r p 2$ QTL detected in the FUMOZ-R pyrethroid-resistant laboratory strain [32], as well as CYP6M4, CYP6S1, CYP4K2 and CYP315A1 that were

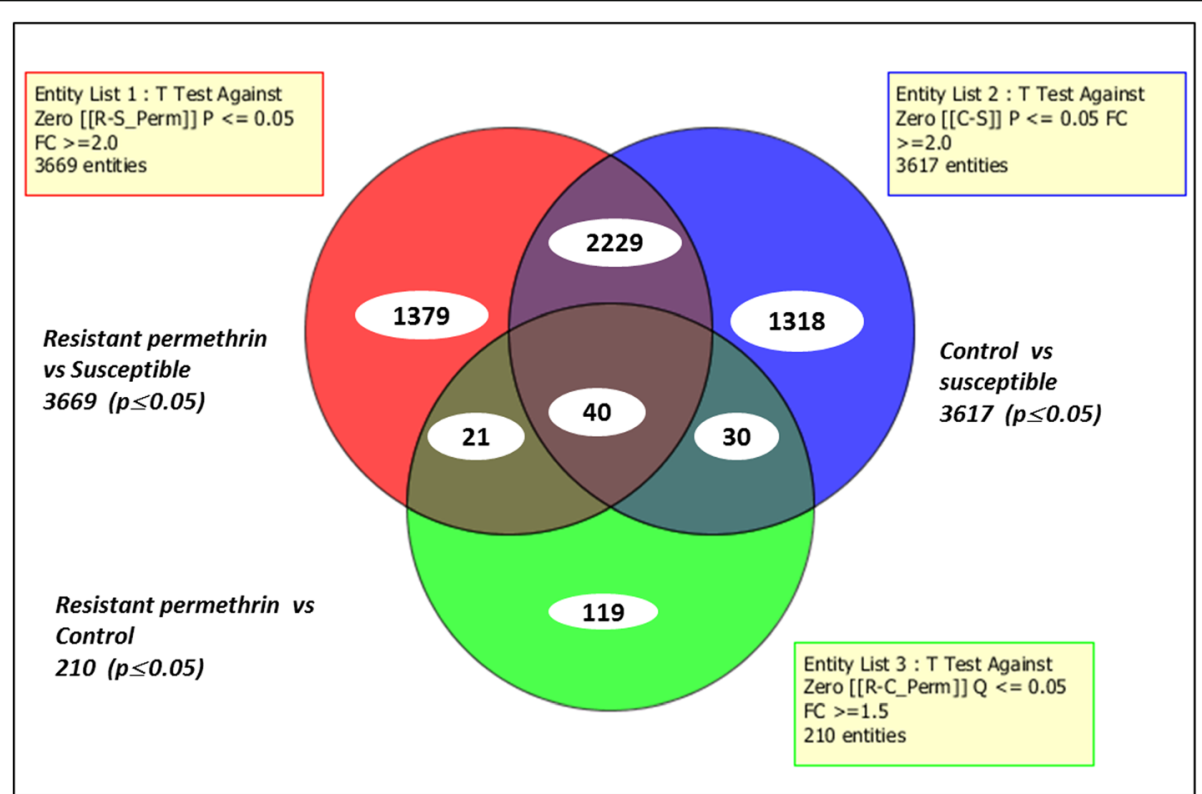

Fig. 1 Summary of transcripts differentially expressed in permethrin resistance. The Venn diagrams show the number of transcripts significantly $(P \leq 0.05)$ up- or downregulated ( $F C \geq 2)$ in each comparison as well as the commonly expressed transcripts 
Table 2 Top detoxification genes upregulated in Rperm-S, C-S and Rperm-C

\begin{tabular}{|c|c|c|c|c|c|c|}
\hline Probe name & Systematic name & $\begin{array}{l}\text { Rperm-S fold } \\
\text { change (FC) }\end{array}$ & $\begin{array}{l}\text { C-S fold } \\
\text { change }(F C)\end{array}$ & $\begin{array}{l}\text { Rperm-C fold } \\
\text { change (FC) }\end{array}$ & $\begin{array}{l}\text { Ortholog in An. } \\
\text { gambiae }\end{array}$ & Description \\
\hline CUST_5822_PI426302897 & Afun005822 & 2.7 & 2.31 & 1.5 & AGAP011496-PA & $\begin{array}{l}\text { AGAP011496-PA [Anopheles } \\
\text { gambiae str. PEST] }\end{array}$ \\
\hline CUST_500_PI426302897 & Afun000500 & 36.2 & 38.1 & & na & Glycogenin \\
\hline CUST_7663_PI426302897 & Afun007663 (CYP6M7) & 34.6 & 28.9 & & AGAP008213-PA & Cytochrome p450 $6 a 8$ \\
\hline CUST_8887_PI426302897 & Afun008887 & 34.0 & 16.8 & & AGAP011997-PA & Nucleotide binding protein 2 \\
\hline CUST_9227_PI426302897 & Afun009227 & 23.3 & 25.6 & & AGAP008141-PA & Argininosuccinate lyase \\
\hline CUST_1459_PI406199769 & combined_c738 & 22.0 & 34.5 & & & Short-chain dehydrogenase \\
\hline CUST_13921_PI426302897 & Afun013921 & 19.1 & 21.1 & & AGAP006709-PA & Chymotrypsin 1 \\
\hline CUST_9492_PI426302897 & Afun009492 & 16.4 & 3.7 & & AGAP001722-PA & Carboxylesterase \\
\hline CUST_1822_PI406199769 & combined_c920 & 11.1 & 11.4 & & & Glutathione-S-transferase gst \\
\hline CUST_45_PI426302897 & Afun000045 (GSTE2) & 10.9 & 15.2 & & AGAP009194-PA & Glutathione-S-transferase gst \\
\hline CUST_4223_PI426302897 & Afun004223 & 10.6 & 9.4 & & AGAP008358-PA & Cytochrome p450 4d1 \\
\hline CUST_12461_PI426302897 & Afun012461 & 8.4 & 10.9 & & AGAP000288-PA & Alcohol dehydrogenase \\
\hline CUST_3220_PI426302897 & Afun003220 & 5.7 & 7.0 & & AGAP002867-PA & Cytochrome p450 \\
\hline CUST_8615_PI426302897 & Afun008615 (CYP6AA1) & 5.2 & 3.8 & & AGAP002862-PA & Cytochrome p450 \\
\hline CUST_9697_PI426302897 & Afun009697 & 4.8 & 6.8 & & AGAP006364-PA & Abc transporter \\
\hline CUST_9_PI426302915 & CYP6M4.seq & 4.8 & 3.5 & & & Cytochrome p450 \\
\hline CUST_13797_PI426302897 & Afun013797 & 4.1 & 3.0 & & AGAP000289-PA & Alcohol dehydrogenase \\
\hline CUST_8445_PI426302897 & Afun008445 (GSTE4) & 3.9 & 4.7 & & AGAP009193-PA & Glutathione-S-transferase gst \\
\hline CUST_25_PI426302915 & CYP6Y2_rvcpl.seq & 3.7 & 3.8 & & & Cytochrome p450 \\
\hline CUST_1392_PI426302897 & Afun001392 & 3.3 & 3.4 & & na & Glycine dehydrogenase \\
\hline CUST_3394_PI426302897 & Afun003394 (CYP315A1) & 3.1 & 2.4 & & AGAP000284-PA & Cytochrome p450 \\
\hline CUST_8909_PI426302897 & Afun008909 (CYP4K2) & 2.4 & 2.0 & & AGAP002416-PA & Cytochrome p450 \\
\hline CUST_20_PI426302915 & CYP6S1.seq & 2.3 & 2.2 & & & Cytochrome p450 \\
\hline CUST_7499_PI426302897 & Afun007499 (GSTD1) & 2.0 & 2.6 & & AGAP004164-PA & Glutathione transferase \\
\hline CUST_11942_PI426302897 & Afun011942 & 6.1 & & & AGAP011509-PA & Carboxylesterase \\
\hline CUST_4048_PI406199772 & CD577343.1 & 5.3 & & & & Cuticle protein \\
\hline CUST_12343_PI426302897 & Afun012343 (CYP4H18) & 5.0 & & & AGAP008358-PA & Cytochrome p450 4d1 \\
\hline CUST_10836_PI426302897 & Afun010836 & 4.8 & & & AGAP006228-PA & Esterase b1 \\
\hline CUST_11042_PI426302897 & Afun011042 & 3.9 & & & AGAP003321-PA & Glycine dehydrogenase \\
\hline CUST_11037_PI426302897 & Afun011037 & 3.7 & & & AGAP003581-PA & Alcohol dehydrogenase \\
\hline CUST_1_PI426302915 & CYP6M1a.seq & 2.9 & & & & Cytochrome p450 \\
\hline CUST_7501_PI406199798 & AGAP007662-RA_2L & 2.6 & & & AGAP007662-RA_2L & Short-chain dehydrogenase \\
\hline CUST_9335_PI426302897 & Afun009335 (CYP6AG1) & 2.4 & & & AGAP003343-PA & Cytochrome p450 \\
\hline CUST_7769_PI426302897 & Afun007769 (CYP9K1) & 2.2 & & & AGAP000818-PA & Cytochrome p450 cyp9k1 \\
\hline CUST_11899_PI426302897 & Afun011899 & 2.1 & & & AGAP012514-PA & Short-chain dehydrogenase \\
\hline CUST_4043_PI406199772 & CD577345.1 & & 3.7 & & & Cuticle protein \\
\hline CUST_7722_PI426302897 & Afun007722 & & 3.2 & & AGAP009850-PA & Abc transporter \\
\hline CUST_12261_PI426302897 & Afun012261 & & 2.8 & & AGAP005758-PA & Carboxylesterase \\
\hline CUST_13481_PI426302897 & Afun013481 (GSTE1) & & 2.7 & & AGAP009195-PA & Glutathione-S-transferase gst \\
\hline CUST_25_PI406199775 & CYP6P9a & & 2.3 & & & Cytochrome p450 \\
\hline CUST_15331_PI426302897 & Afun015331 (CYP307A1) & & 2.2 & & AGAP001039-PB & Cytochrome p450 307a1 \\
\hline CUST_493_PI426302897 & Afun000493 & & 2.1 & & AGAP006225-PA & Aldehyde oxidase \\
\hline
\end{tabular}


expressed at lower levels $(\mathrm{FC}<5)$ (Table 2). Transcripts from the glutathione S-transferase (GST) family notably from epsilon [GSTe2 (FC of 10.9 in $\mathrm{R}_{\text {perm }}-\mathrm{S}$ and 15.2 in C-S) and GSTe4 (FC of 3.9 in $\mathrm{R}_{\text {perm }}-\mathrm{S}$ and 4.7 in C-S)] and delta, GSTd1-5 (FC 2.0 and 2.6 in $\mathrm{R}_{\text {perm }}-\mathrm{S}$ and $\mathrm{C}-\mathrm{S}$, respectively) classes were upregulated. Other genes such as $A B C$ transporter (Afun009697), alcohol dehydrogenases (Afun012461, Afun013797), carboxylesterase (Afun009492), short chain dehydrogenase (combined_c738) and chymotrypsin (Afun013921) were also overexpressed (Table 2 and Additional file 1: Table S1).

\section{Comparative transcriptional profiling of DDT and permethrin resistance}

A comparative analysis of transcriptomes associated with DDT resistance in Kpome showed a total of 2158 transcripts differentially expressed ( $\geq 2$-fold change, $\mathrm{FC}$ at $P \leq 0.05$ ) in $\mathrm{R}_{\mathrm{DDT}}-\mathrm{S}$ with 715 upregulated and 1443 downregulated. The comparison between $R_{D D T}-S, R_{\text {perm }}-S$ and C-S revealed 1311 transcripts differentially expressed. A set of 212 transcripts was commonly expressed between $\mathrm{R}_{\mathrm{DDT}}-\mathrm{S}$ and $\mathrm{R}_{\text {perm }}-\mathrm{S}$, 958 transcripts and 270 transcripts were also expressed when comparing $\mathrm{R}_{\text {perm }}-\mathrm{S}$ and $\mathrm{R}_{\mathrm{DDT}}-\mathrm{S}$ to C-S (Fig. 2).

\section{Genes commonly overexpressed in $\mathrm{R}_{\mathrm{DDT}}-\mathrm{S}$, Rperm-S and \\ C-S comparisons}

Many genes were commonly overexpressed in the three comparisons with glycogenin (Afun000500) and arginosuccinate lyase (Afun009227) been the most overexpressed and were consistent in all the three comparisons with fold change of (FC 36.2, 38.1 and 41.4) and (FC
22.2, 23.3 and 25.6) in $\mathrm{R}_{\mathrm{DDT}}-\mathrm{S}, \mathrm{R}_{\text {perm }}-\mathrm{S}$ and C-S, respectively. Among the common detoxification gene families identified, the GSTe2 gene (Afun000045) was the one that remained highly upregulated with FC of 13.3, 10.9 and 15.2 for $\mathrm{R}_{\mathrm{DDT}}-\mathrm{S}, \mathrm{R}_{\text {perm }}-\mathrm{S}$ and C-S, respectively. The CYP6M7 gene was also overexpressed in all three comparisons; FC was 34.6 in $\mathrm{R}_{\text {perm }}-\mathrm{S}$ and FC 28.9 in C-S but with lower FC of 4 in $\mathrm{R}_{\mathrm{DDT}}-\mathrm{S}$. Several other genes of the family of P450 such as CYP6AA1, CYP6M4, CYP6Y2, CYP4K2 and CYP315A1 were also upregulated. Other transcripts of the GST family were also upregulated such as the Gste4 (FC 4.3, 3.9 and 4.7 in $\mathrm{R}_{\mathrm{DDT}}-\mathrm{S}, \mathrm{R}_{\text {perm }}-\mathrm{S}$ and C-S, respectively) and the GSTd1 (FC 2.2, 2.0 and 2.6 in $\mathrm{R}_{\mathrm{DDT}}-\mathrm{S}, \mathrm{R}_{\text {perm }}-\mathrm{S}$ and $\mathrm{C}-\mathrm{S}$, respectively (Table 3 and Additional file 1: Table S2).

\section{Overexpressed genes in the comparison between $\mathrm{R}_{\mathrm{DDT}}-\mathrm{S}$ and Rperm-S}

A limited number of genes were commonly overexpressed in these two "resistant" comparisons, potentially as a result of induction or greater involvement in resistance than in control samples. The transcript of alcohol dehydrogenase (Afun011037) was the most overexpressed in $\mathrm{R}_{\mathrm{DDT}}-\mathrm{S}$, and $\mathrm{R}_{\text {perm }}-\mathrm{S}$ comparison with FC 6.5 and 3.7, respectively. Other genes of the P450 family including CYP4H18, CYP9K1, CYP9J3, and the esterase $b 1$ were also overexpressed (Table 3 and Additional file 1: Table S2).

\section{Overexpressed genes in the comparison between $\mathrm{R}_{\mathrm{DDT}} \mathrm{S}$ and C-S}

The transcript (combined_c738) belonging to the shortchain dehydrogenase gene was the most commonly

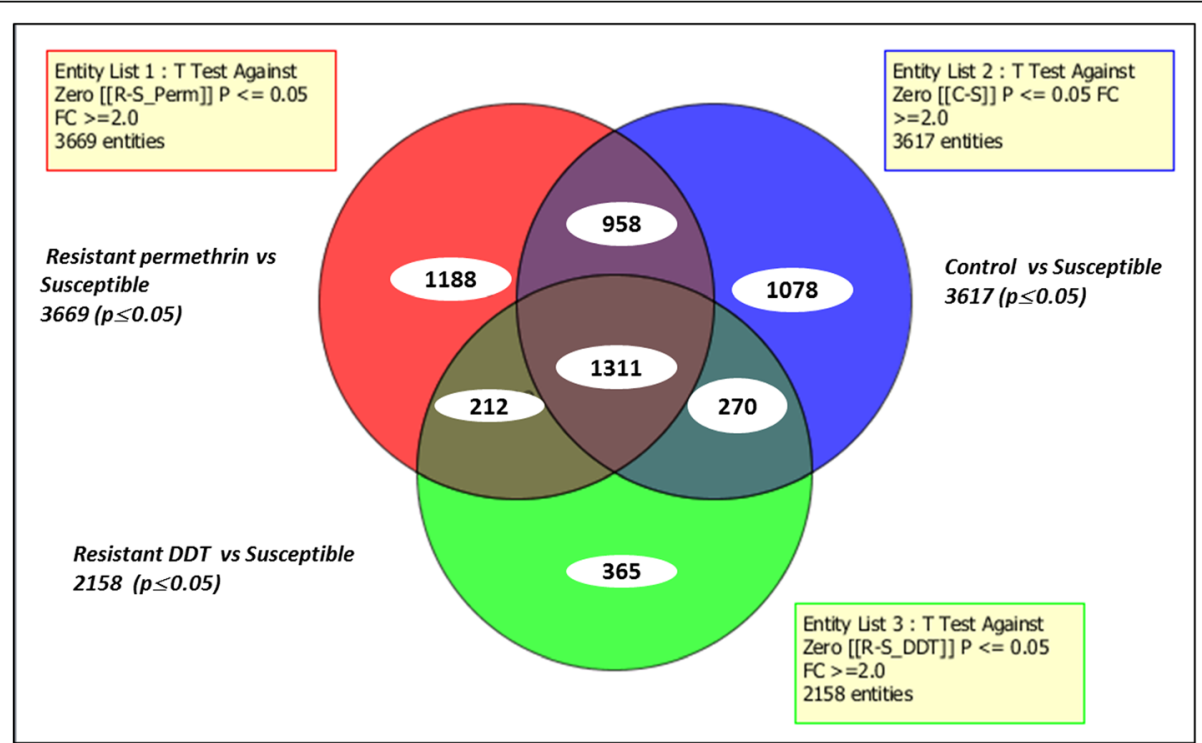

Fig. 2 Summary of transcripts differentially expressed in DDT and permethrin resistance. The Venn diagrams show the number of transcripts significantly $(P \leq 0.05)$ up- or downregulated ( $F C \geq 2)$ in each comparison as well as the commonly expressed transcripts permethrin 
Table 3 Top detoxification genes upregulated in $\mathrm{R}_{\mathrm{DDT}}-\mathrm{S}$, Rperm-S and C-S

\begin{tabular}{|c|c|c|c|c|c|c|}
\hline Probe name & Systematic name & $\begin{array}{l}\mathrm{R}_{\mathrm{DDT}}-\mathrm{S} \text { fold } \\
\text { change (FC) }\end{array}$ & $\begin{array}{l}\text { Rperm-S fold } \\
\text { change (FC) }\end{array}$ & $\begin{array}{l}\text { C-S fold } \\
\text { change (FC) }\end{array}$ & $\begin{array}{l}\text { Ortholog in An. } \\
\text { gambiae }\end{array}$ & Description \\
\hline CUST_500_PI426302897 & Afun000500 & 36.2 & 38.1 & 41.4 & na & Glycogenin \\
\hline CUST_9227_PI426302897 & Afun009227 & 22.2 & 23.3 & 25.6 & AGAP008141-PA & Argininosuccinate lyase \\
\hline CUST_45_PI426302897 & Afun000045 (GSTE2) & 13.3 & 10.9 & 15.2 & AGAP009194-PA & Glutathione-S-transferase \\
\hline CUST_4223_PI426302897 & Afun004223 & 12.8 & 10.6 & 9.4 & AGAP008358-PA & Cytochrome p450 4d1 \\
\hline CUST_9697_PI426302897 & Afun009697 & 11.6 & 4.8 & 6.8 & AGAP006364-PA & Abc transporter \\
\hline CUST_1822_PI406199769 & combined_c920 & 11.5 & 11.1 & 11.4 & & Glutathione-S-transferase \\
\hline CUST_3220_PI426302897 & Afun003220 & 10.8 & 5.7 & 7.0 & AGAP002867-PA & Cytochrome p450 \\
\hline CUST_9492_PI426302897 & Afun009492 & 7.9 & 16.4 & 3.7 & AGAP001722-PA & Carboxylesterase \\
\hline CUST_8615_PI426302897 & Afun008615 (CYP6AA1 ) & 5.1 & 5.2 & 3.8 & AGAP002862-PA & Cytochrome p450 \\
\hline CUST_9_PI426302915 & CYP6M4.seq & 4.9 & 4.8 & 3.5 & & Cytochrome p450 \\
\hline CUST_8445_PI426302897 & Afun008445 (GSTE4) & 4.3 & 3.9 & 4.7 & AGAP009193-PA & Glutathione-S-transferase \\
\hline CUST_6930_PI426302897 & Afun006930 (CYP6M7) & 4.0 & 34.6 & 28.9 & AGAP008212-PA & Cytochrome p450 6a8 \\
\hline CUST_25_PI426302915 & CYP6Y2_rvcpl.seq & 3.4 & 3.7 & 3.8 & & Cytochrome p450 \\
\hline CUST_20_PI426302915 & CYP6S1.seq & 3.0 & 2.3 & 2.2 & & Cytochrome p450 \\
\hline CUST_8909_PI426302897 & Afun008909 (CYP4K2) & 2.8 & 2.4 & 2.0 & AGAP002416-PA & Cytochrome p450 \\
\hline CUST_1392_PI426302897 & Afun001392 & 2.5 & 3.3 & 3.4 & na & Glycine dehydrogenase \\
\hline CUST_13218_PI426302897 & Afun013218 (CYP315A1) & 2.3 & 2.9 & 2.6 & AGAP000284-PA & Cytochrome p450 \\
\hline CUST_7499_PI426302897 & Afun007499 (GSTD1) & 2.2 & 2.0 & 2.6 & AGAP004164-PA & Glutathione transferase \\
\hline CUST_11037_PI426302897 & Afun011037 & 6.5 & 3.7 & & AGAP003581-PA & Alcohol dehydrogenase \\
\hline CUST_12343_PI426302897 & Afun012343 (CYP4H18 ) & 5.2 & 5.0 & & AGAP008358-PA & Cytochrome p450 4d1 \\
\hline CUST_10836_PI426302897 & Afun010836 & 4.3 & 4.8 & & AGAP006228-PA & Esterase b1 \\
\hline CUST_7769_PI426302897 & Afun007769 (CYP9K1 ) & 3.0 & 2.2 & & AGAP000818-PA & Cytochrome p450 cyp9k1 \\
\hline CUST_7469_PI426302897 & Afun007469 (CYP9J3) & 2.0 & 2.1 & & AGAP012296-PA & Cytochrome p450 \\
\hline CUST_12461_PI426302897 & Afun012461 & & 8.4 & 10.9 & AGAP000288-PA & Alcohol dehydrogenase \\
\hline CUST_3489_PI406199769 & combined_c1762 & & 2.2 & 2.2 & & Abc transporter \\
\hline CUST_8026_PI426302897 & Afun008026 & & 2.1 & 2.2 & AGAP003578-PA & Aldehyde dehydrogenase \\
\hline CUST_1458_PI406199769 & combined_c738 & 10.4 & & 15.9 & & Short-chain dehydrogenase \\
\hline CUST_4043_PI406199772 & CD577345.1 & 4.4 & & 3.7 & & Cuticle protein \\
\hline CUST_15331_PI426302897 & Afun015331 (CYP307A1) & 3.4 & & 2.2 & AGAP001039-PB & Cytochrome p450 307a1 \\
\hline CUST_25_PI406199775 & CYP6P9a & 2.8 & & 2.3 & & Cytochrome p450 \\
\hline CUST_13481_PI426302897 & Afun013481 (GSTE1 ) & 2.5 & & 2.7 & AGAP009195-PA & Glutathione-S-transferase gst \\
\hline CUST_4048_PI406199772 & CD577343.1 & & 5.3 & & & Cuticle protein \\
\hline CUST_11042_PI426302897 & Afun011042 & & 3.9 & & AGAP003321-PA & Glycine dehydrogenase \\
\hline CUST_1_PI426302915 & CYP6M1a.seq & & 2.9 & & & Cytochrome p450 \\
\hline CUST_9335_PI426302897 & Afun009335 (CYP6AG1) & & 2.4 & & AGAP003343-PA & Cytochrome p450 \\
\hline CUST_13475_PI426302897 & Afun013475 & 3.2 & & & AGAP003582-PA & Alcohol dehydrogenase \\
\hline CUST_5448_PI426302897 & Afun005448 (CYP302A1) & 2.6 & & & AGAP005992-PA & Cytochrome p450 \\
\hline CUST_4047_PI406199772 & CD577343.1 & 2.4 & & & & Cuticle protein \\
\hline CUST_8823_PI426302897 & Afun008823 (CYP4D15 ) & 2.4 & & & AGAP002418-PA & Cytochrome p450 \\
\hline CUST_7301_PI426302897 & Afun007301 (CYP4J5) & 2.2 & & & AGAP006048-PA & Cytochrome p450 \\
\hline CUST_208_PI406199788 & $\mathrm{gb}-\mathrm{CYP} 12 \mathrm{F3}$ & 2.1 & & & & Cytochrome p450 \\
\hline CUST_10630_PI426302897 & Afun010630 & 2.1 & & & AGAP002866-PA & Cytochrome p450 \\
\hline CUST_7722_PI426302897 & Afun007722 & & & 3.2 & AGAP009850-PA & Abc transporter \\
\hline
\end{tabular}


Table 3 Top detoxification genes upregulated in $\mathrm{R}_{\mathrm{DDT} T}-\mathrm{S}$, Rperm-S and C-S (Continued)

\begin{tabular}{|c|c|c|c|c|c|c|}
\hline Probe name & Systematic name & $\begin{array}{l}\mathrm{R}_{\mathrm{DDT}}-\mathrm{S} \text { fold } \\
\text { change }(\mathrm{FC})\end{array}$ & $\begin{array}{l}\text { Rperm-S fold } \\
\text { change (FC) }\end{array}$ & $\begin{array}{l}\text { C-S fold } \\
\text { change (FC) }\end{array}$ & $\begin{array}{l}\text { Ortholog in An. } \\
\text { gambiae }\end{array}$ & Description \\
\hline CUST_12261_PI426302897 & Afun012261 & & & 2.8 & AGAP005758-PA & Carboxylesterase \\
\hline CUST_4088_PI406199772 & CD577323.1 & & & 2.4 & & Cuticle protein \\
\hline CUST_493_PI426302897 & Afun000493 & & & 2.1 & AGAP006225-PA & Aldehyde oxidase \\
\hline
\end{tabular}

Abbreviation: na not available

upregulated in the $\mathrm{R}_{\mathrm{DDT}}-\mathrm{S}$, and C-S comparison with $\mathrm{FC}$ 10.4 and 15.9 , respectively. The cytochrome $\mathrm{P} 450$ gene CYP307A1 was also upregulated with FC 3.3 in $\mathrm{R}_{\mathrm{DDT}}-\mathrm{S}$ and FC 2.2 in C-S. The CYP6P9a gene, reported to be upregulated in southern Africa mosquitoes, was also upregulated with FC 2.8 and 2.3 in $\mathrm{R}_{\mathrm{DDT}^{-}} \mathrm{S}$ and $\mathrm{C}-\mathrm{S}$, respectively. Other genes with a known association with insecticide resistance were also upregulated in Kpome mosquitoes as shown in Table 3 and Additional file 1: Table S2.

\section{Overexpressed genes in the comparison between Rperm-S and C-S}

Genes identified from these comparisons include the alcohol dehydrogenase gene (Afun012461 ortholog of AGAP000288 in An. gambiae) which is consistently upregulated in $\mathrm{R}_{\text {perm }}$-S (FC8.4) and C-S (FC10.9) but not in $\mathrm{R}_{\mathrm{DDT}} \mathrm{S}$. Similarly, the aldehyde dehydrogenase (Afun0 08026) and the $A B C$ transporter (Combined_c1762) were also upregulated in $\mathrm{R}_{\text {perm }}-\mathrm{S}$ and C-S exclusively although with lower FC.

\section{Overexpressed genes in the comparison between DDT resistant mosquitoes and a susceptible strain}

Some detoxification genes specific for $\mathrm{R}_{\mathrm{DDT}^{-}} \mathrm{S}$ comparison were identified in Kpome. These genes include alcohol dehydrogenase Afun013475 (FC 3.2), the most upregulated gene (FC 3.2) as well as CYP302A1 (FC 2.6), CYP4D15 (FC 2.4), CYP4J5 (FC 2.2), $g b-C Y P 12 F 3$ (FC 2.1) and the cytochrome P450 (Afun010630) (FC 2.1).

\section{Overexpressed genes in the comparison between} permethrin resistant mosquitoes and a susceptible strain For $\mathrm{R}_{\text {perm }} \mathrm{S}$ comparison, the $A B C$ transporter (Afun 007722) was the most upregulated gene with a fold change of 3.2. Also, the carboxylesterase (Afun012261) (FC 2.8), the cuticle protein (CD5773231) (FC 2.4) and the aldehyde oxidase (Afun00493) (FC 2.4) were upregulated.

\section{Quantitative reverse transcriptase PCR}

A qRT-PCR analysis revealed that GSTe2 is the most overexpressed genes in DDT and permethrin resistant samples (FC 16.0 and 18.1, respectively) analysed in this study. However, the expression level of the detoxification gene, CYP6M7 recorded with the qRT-PCR analysis was lower (FC 1.4 and 1.7 in permethrin and DDT resistant samples, respectively) compared to expression level from microarray analysis (FC 34.6 and 4.0 in permethrin and DDT resistant samples, respectively). The GSTd1-5 and the GSTd3 were significantly upregulated in DDT resistant samples (FC 12.5 and $6.2 ; P<0.01$ ) compared to permethrin resistant samples (FC 0.72 and $0.86 ; P<$ 0.05) (Fig. 3a, b).

Role of the knockdown resistance gene in DDT and permethrin resistance profiles recorded in An. funestus from Kpome

Amplification and sequencing of a fragment (a portion of intron 19 and the entire exon 20, domain II, segment 6) of the VGSC gene showed that both L1014F (TTAto-TTT) and L1014S (TTA-to-TCA) kdr mutation commonly found in An. gambiae are absent in this mosquito species. However, further analysis with 837 bp of common sequences generated from the eleven mosquitoes analysed revealed 12 polymorphic sites with 12 haplotypes (Table 4, Fig. 4) showing a high genetic diversity of this gene within the An. funestus mosquitoes of Kpome. No amino acid change was detected in the Benin population. Furthermore, the Tajima D and $\mathrm{Fu}$ and Li D* statistics (Table 4) were not statistically significant. The Neighbour-joining tree showed low genetic differentiation between Benin populations compared to Cameroon samples with respect to geographical distance (Fig. 4).

\section{Discussion}

The WHO Global Plan for Insecticide Resistance Management [12] highlights the necessity to detect and monitor the development of insecticide resistance and characterise the underlying resistance mechanisms to maintain the successes in the reduction of malaria cases across Africa. In this study, we elucidated the molecular basis driving DDT and pyrethroids resistance in an inland $A n$. funestus population from Benin. 

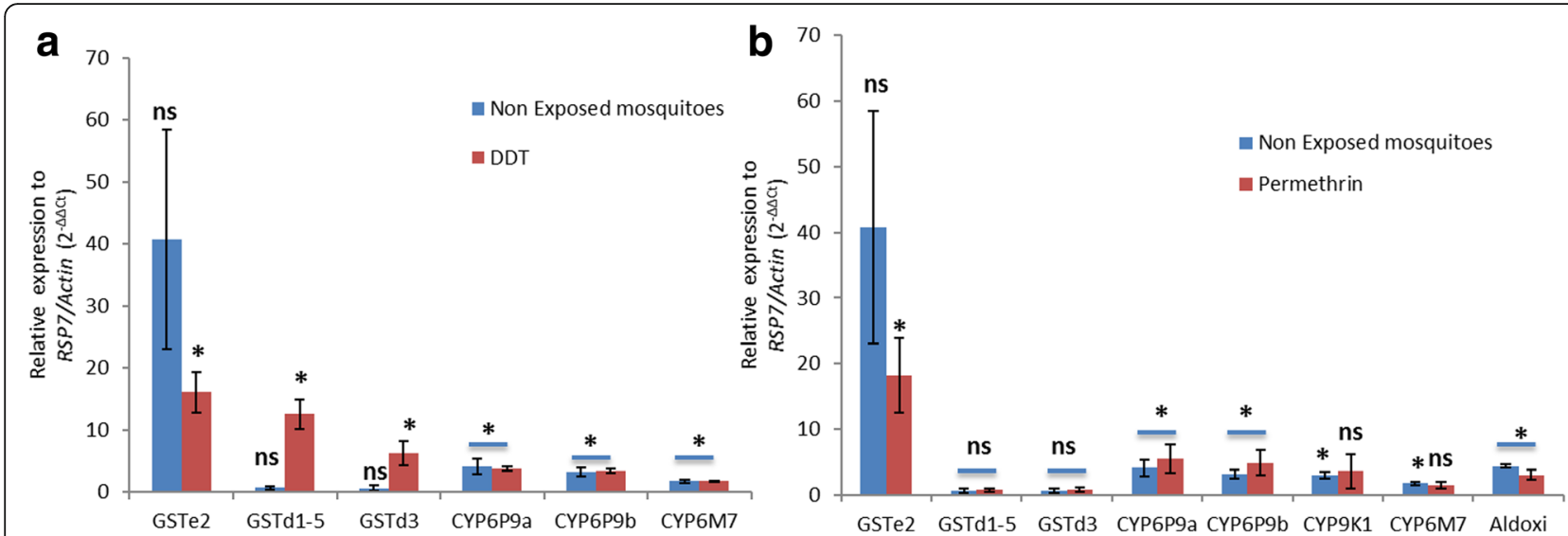

Fig. 3 Quantitative PCR results: differential expression by qRT-PCR of some candidate genes upregulated in microarray assays in An. funestus resistant to DDT (a) and permethrin $(\mathbf{b})$. Error bars represent SD $(n=3)$. The presence of * on top of the two-fold changes for each gene indicates a statistically significant $(P<0.05)$ over-expression in resistant or non-exposed mosquitoes compared to the FANG susceptible strain; "ns" is shown when the difference was not significant

\section{Permethrin and DDT resistance in An. funestus from Kpome is driven by metabolic resistance}

Transcriptional profiling results and the absence of $k d r$ mutation points out to a possible metabolic mechanism driving permethrin and DDT resistance in An. funestus from Kpome notably through overexpression of genes involved in insecticide detoxification such as cytochrome P450 genes, GSTs, aldehyde oxidases, and other gene families previously associated with resistance of $A n$. funestus to insecticides [41].

The cytochrome P450, CYP6M7 was the most overexpressed detoxification gene in permethrin exposed mosquitoes compared to the FANG susceptible strain as well as to the unexposed mosquitoes from microarrays analysis. However, this consistent information from microarray analysis was not confirmed by qRT-PCR. This discrepancy could be associated with the high genetic redundancy of some P450 genes and a high level of sequence similarity between different genes. These factors could lead to cross amplification contributing to homogenise the expression between samples. It is more likely that CYP6M7 could also be a key pyrethroid resistance gene in Benin, but further validation is required. New approaches with RNAseq could help to confirm the expression pattern of this gene. On the other hand, only one gene (AGAP011496-PA) was commonly expressed in $\mathrm{R}_{\text {perm }}-\mathrm{S}, \mathrm{C}-\mathrm{S}$ and $\mathrm{R}_{\text {perm }}-\mathrm{C}$ comparisons. This could be due to the high resistance recorded against permethrin suggesting a less significant difference between the resistant and the control. Such a low number of differentially expressed genes between R-S and C-S comparison is commonly observed in similar studies when the resistance level is high in the population as it is the case here in Kpome [24, 27]. This is because both non-exposed (control; C) and alive mosquitoes after exposure (resistant; R) are all resistant which leads to less difference in the level of gene expression fold change between these two comparisons. The GSTe2 gene was the most upregulated gene in both DDT and permethrin resistant samples showing that this gene is likely to be involved in both DDT and permethrin resistance as previously shown in coastal Benin [27]. Hence, such genes could confer cross-resistance to both insecticides, and this represents a challenge for the success of the malaria control

Table 4 Summary statistics for polymorphism in the voltage-gated sodium channel gene in $F_{0}$ An. funestus from Kpome compared to Pahou and Cameroon population

\begin{tabular}{|c|c|c|c|c|c|c|c|c|c|c|}
\hline & $N$ & $S$ & $\pi$ & k & $h$ & hd & Syn & Nonsyn & $\begin{array}{l}\mathrm{D} \\
(P \text {-value })\end{array}$ & $\begin{array}{l}\mathrm{D}^{*} \\
(P \text {-value })\end{array}$ \\
\hline Kpome & 22 & 12 & 0.00351 & 2.93939 & 12 & 0.909 & 0 & 0 & $\begin{array}{l}0.37 \\
(P>0.10)\end{array}$ & $\begin{array}{l}0.32 \\
(P>0.10)\end{array}$ \\
\hline Pahou & 20 & 10 & 0.00260 & 2.17895 & 12 & 0.905 & 0 & 0 & $\begin{array}{l}0.79 \\
(P>0.10)\end{array}$ & $\begin{array}{l}0.96 \\
(P>0.10)\end{array}$ \\
\hline Cameroon & 40 & 37 & 0.00514 & 4.30128 & 29 & 0.977 & 2 & 3 & $\begin{array}{l}1.81 \\
(P>0.10)\end{array}$ & $\begin{array}{l}2.75 \\
(P>0.10)\end{array}$ \\
\hline
\end{tabular}

Abbreviations: $N$ number of sequences (2n), $S$ number of polymorphic sites, $h$ number of haplotypes, $h d$ haplotype diversity, $\pi$ nucleotide diversity, $k$ mean number of nucleotide differences, $D$ Tajima's test, $D^{*} \mathrm{Fu}$ and Li's test, Syn synonymous mutation, Nonsyn non synonymous mutation 


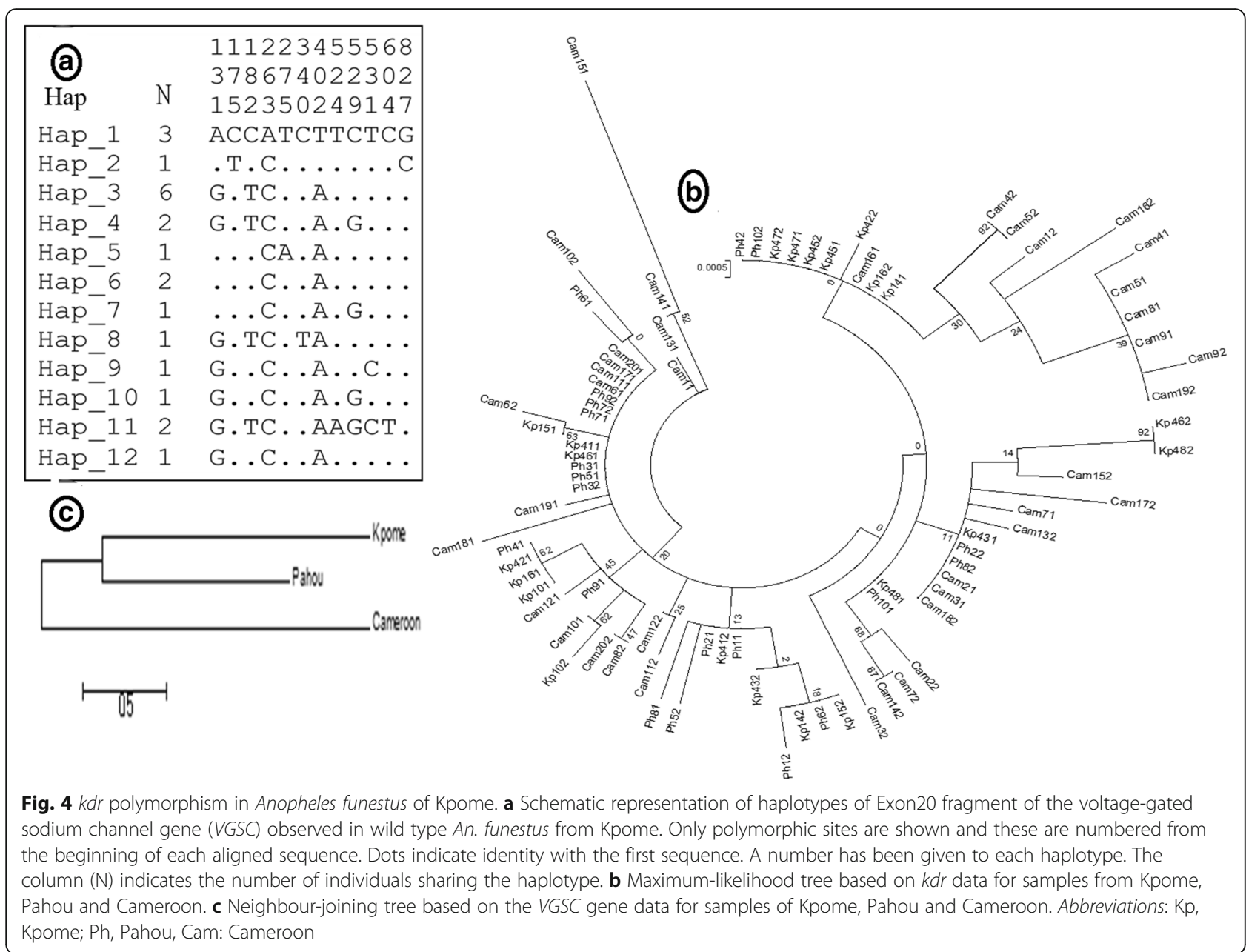

program. The enzyme encoded by this gene was shown to be able to metabolize both DDT and permethrin [27]. QRT-PCR confirmed the expression level of GSTe2 in permethrin, DDT resistant and unexposed mosquitoes compared to the susceptible FANG. This observation is in line with the common implication of the GSTe2 gene in permethrin and DDT resistance in the An. funestus population from Pahou (Benin) reported by Riveron et al. [27]. Furthermore, the potential role of GSTe2 in permethrin resistance observed here has been shown in previous reports that suggested that orthologs of GSTe2 in other insects are associated with pyrethroids resistance. Indeed, the elevated GSTe2 expression has been associated with pyrethroid resistance by acting as a pyrethroid-binding protein and sequestering the insecticide [42] or by protecting against oxidative stress and lipid peroxidation induced by pyrethroid exposure [43]. In the yellow fever mosquito Ae. aegypti, a partial knockdown of the ortholog of GSTe2 led to increased mortality to pyrethroids (deltamethrin), indicating that GSTe2 is also associated with deltamethrin resistance in $A e$. aegypti [44]. Moreover, the over-expression of GSTe2 was observed with the high frequency of the $119 \mathrm{~F}$ resistant allele in Kpome (91\% of 119F/F homozygote resistant genotype) [10]. The near fixation of 119F-GSTe2 resistant allele in Kpome, which enlarges the substrate binding sites to increase DDT metabolism [27], coupled with the high overexpression of GSTe2 highlights the key role played by this gene in DDT resistance as previously observed in Pahou. Orthologs of GSTe2 have also been shown to be associated with DDT resistance in other mosquito species such as An. gambiae and Ae. aegypti [33, 44, 45]. Overall, GSTe2 can confer resistance to DDT and permethrin, and this cross-resistance to pyrethroids is of significant concern for malaria control as GSTe2 could protect mosquitoes against the major insecticides used to impregnate LLINs in public health. However, the overexpression of several genes from other gene families in this study highlights the complexity of resistance mechanisms suggesting the involvement of other genes than just GSTe2. In addition, the transcription profile of the duplicated genes CYP6P9 $a$ and CYP6P9b (which can metabolise both types I and II pyrethroids as shown by Riveron et al. [27]) in pyrethroid 
resistance in Kpome is different to that observed for $A n$. funestus population in southern Africa. Indeed these P450 genes were highly upregulated in pyrethroidresistant laboratory and field population from southern Africa $[9,15,16,31,46,47]$ while a lower level of overexpression was recorded in Kpome. The level of expression of CYP6P9a and CYP6P9b recorded in Kpome An. funestus population is similar to what was observed previously in Pahou population (coastal Benin). This result suggests that the two duplicated $\mathrm{P} 450$ genes are not strongly associated with permethrin resistance in Benin as observed in Mozambique (southern Africa) $[15,35]$. Therefore, the molecular basis of the pyrethroid resistance in Benin is most likely different to that in southern Africa pointing to independent selection events of the pyrethroid resistance across Africa probably under different local selective forces. These different selective pressures could be increased of ITNs coverage across Benin, agricultural use of pesticides $[48,49]$ and spilt petroleum products [50]. In most African urban areas, insecticides are used for domestic purposes, including the control of mosquitoes in the form of mosquito coils, fumigation bombs or sprays [51]. These insecticides are used in an uncontrolled and heterogeneous manner in term of coverage and doses of insecticides in each household. Such practices may represent an additional selective pressure favouring pyrethroid resistance. The presence of agrochemicals, or industrial pollutants and plant compounds in mosquito breeding sites could also affect insecticide tolerance by modulating mosquito detoxification systems [52]. Concerning DDT resistance, in addition to the GSTe2 gene, two other detoxification genes of GST family were also upregulated: GSTd1-5 and GSTd3. GSTd3 was shown to be upregulated in DDT-resistant An. arabiensis from an urban site in Burkina Faso [53]. GSTd1-5 have been previously implicated in coding for enzymes that directly metabolise DDT or have at least been previously associated with the DDT-resistant phenotype [54,55]. Further validation of the role of these genes in DDT resistance is required. The two duplicated cytochrome $\mathrm{P} 450$ genes, CYP6P9a $(\mathrm{FC}=3.7)$ and CYP6P9b $(\mathrm{FC}=3.9)$, which confer pyrethroid resistance in southern African populations of An. funestus [24] were also upregulated in the Benin population. However, because their encoded proteins are unable to metabolise DDT [24], these genes are not likely involved in DDT resistance observed in Kpome mosquitoes. Nevertheless, further investigation is required to validate this hypothesis. Monitoring the insecticide resistance mechanisms that occur within a population should be an essential component to all insecticide-based vector control programs and improving resistance management involves a better understanding of resistance mechanisms.
These data contribute to the growing body of knowledge focussed on pyrethroid and DDT resistance in Benin. This situation emphasises the need for natural resistance and vector monitoring so that adjustments to control programmes can be made timeously and accurately.

\section{Analysis of polymorphisms of the VGSC gene supports a limited role of knockdown resistance}

Mechanisms of DDT and permethrin resistance are likely not associated with target site resistance as no $\mathrm{kdr}$ mutation was detected in analysed mosquitoes from Kpome. L1014F or L1014S change commonly associated with pyrethroid/DDT resistance in $A n$. gambiae was not detected in this population of $A n$. funestus, as it was also the case for all populations of this species, analysed so far [9, 19-22]. This suggests that the VGSC is probably evolving neutrally in DDT and permethrin resistance in An. funestus population.

Furthermore, the neutrality tests with Tajima D and $\mathrm{Fu}$ and $\mathrm{Li} \mathrm{D*}$ statistics revealed no signature of directional selection on the sodium channel gene suggesting the limited role of knockdown resistance in both DDT and pyrethroid resistance in An. funestus in Kpome. The neighbour-joining tree revealed that Kpome mosquitoes cluster with Pahou mosquitoes while they are different to Cameroon mosquitoes. This reveals a reduced gene flow between these populations probably through isolation by distance which can also affect the spread of insecticide resistance genes in this species as previously shown for $A n$. funestus populations across the continent [56].

\section{Conclusions}

Metabolic resistance is likely driving resistance to both pyrethroids (permethrin) and DDT in the major malaria vector An. funestus in Benin. The glutathione s-transferase gene, GSTe2 is playing a key role in DDT resistance and most likely is responsible for the observed cross-resistance to pyrethroids in An. funestus populations from Kpome and such cross-resistance should be taken into account for the implementation of future insecticide resistance management strategies. Moreover, this study provides knowledge on the resistance profile and underlying resistance mechanisms to the available insecticides in $A n$. funestus, a less studied malaria vector in Benin, in order to develop better insecticide resistance diagnostics. Further investigation should be performed on the expression level of target genes to ascertain the role of metabolic mechanisms in DDT and permethrin resistance in this An. funestus population. Resistance mechanisms detected in this studied population appear to be different from those identified in other African regions 
showing the need to characterise mosquito populations at country-level for more appropriate and tailored control interventions.

\section{Additional file}

Additional file 1: Table S1. The most upregulated genes in Rperm-S, $\mathrm{C}-\mathrm{S}$ and Rperm-C. Table S2. The most upregulated genes in $\mathrm{R}_{\mathrm{DDT}}-\mathrm{S}$, Rperm-S and C-S comparisons. (DOCX 56 kb)

\section{Abbreviations}

DDT: Dichlorodiphenyltrichloroethane; LSTM: Liverpool School of Tropical Medicine; GRT-PCR: Quantitative reverse transcriptase polymerase chain reaction; VGSC: Voltage-gated sodium channel; WHO: World Health Organisation

\section{Acknowledgements}

We appreciate Kpome community for their cooperation during fieldwork. We thank Innocent Djegbe, Eric Tossou, Gareth Weedall, Claude Gande and Murielle Soglo for their technical assistance and relevant advice.

\section{Funding}

The Wellcome Trust supports this work grants Reference 099864/Z/12/Z awarded to RD and a Wellcome Trust Senior Research Fellowship in Biomedical Sciences to CSW (101893/Z/13/Z).

\section{Availability of data and materials}

All data generated or analysed during this study are included in this published article and its Additional file.

\section{Authors' contributions}

$\mathrm{RD}$ and CSW designed the study. GT and RA carried out mosquito collection and GT, RA, AM and JR reared mosquitoes and performed WHO bioassays. GT and HI performed microarray, QRT-PCR analyses and sequencing of resistance genes. GT, JMR and CSW analyzed data. AY gave advise on the study design and contributed to the implementation of the study. GT, RD, AY, JMR and CSW wrote the manuscript. All authors read and approved the final manuscript.

\section{Ethics approval and consent to participate}

Verbal consent was obtained from household heads before mosquito collections.

\section{Consent for publication}

Not applicable.

\section{Competing interests}

The authors declare that they have no competing interests.

\section{Publisher's Note}

Springer Nature remains neutral with regard to jurisdictional claims in published maps and institutional affiliations.

\section{Author details}

'International Institute of Tropical Agriculture, Cotonou 08 BP 0932, Benin ${ }^{2}$ University of Abomey Calavi, BP 526 Cotonou, Benin. ${ }^{3}$ Liverpool School of Tropical Medicine, Pembroke Place, Liverpool L3 5QA, UK. ${ }^{4}$ Cell Biology and Genetics Unit, Department of Zoology, University of Ibadan, Ibadan, Oyo State, Nigeria. ${ }^{5}$ LSTM Research Unit at the Centre for Research in Infectious Diseases (CRID), P.O. Box 13591, Yaoundé, Cameroon.

Received: 28 February 2018 Accepted: 18 September 2018 Published online: 20 November 2018

\section{References}

1. WHO. World Malaria Report 2016. Geneva: World Health Organisation; 2016. http://www.who.int/malaria/publications/world-malaria-report-2016.
2. WHO. World Malaria Report 2011. Geneva: World Health Organisation; 2011. http://www.who.int/malaria/world_malaria_report_2011/en/.

3. Fontenille $D$, Simard F. Unravelling complexities in human malaria transmission dynamics in Africa through a comprehensive knowledge of vector populations. Comp Immunol Microbiol Infect Dis. 2004;27:357-75.

4. WHO. World Malaria Report 2014. Geneva: World Health Organisation; 2014. http://www.who.int/malaria/publications/world_malaria_report_ 2014/report/en/.

5. Ranson H, Lissenden N. Insecticide resistance in African Anopheles mosquitoes: a worsening situation that needs urgent action to maintain malaria control. Trends Parasitol. 2016;32:187-96.

6. Hamon J, Abonnenc E, Noel E. Contribution à l'étude des Culicidés de l'Ouest du Sénégal. Ann Parasitol Hum Comp. 1955;30:278-308.

7. Akogbéto $\mathrm{M}$, Yakoubou S. Resistance of malaria vectors to pyrethrins used for impregnating mosquito nets in Benin, West Africa. Bull Soc Pathol Exot. 1999;92:123-30

8. Corbel V, N'Guessan R, Brengues C, Chandre F, Djogbenou L, Martin T, et al. Multiple insecticide resistance mechanisms in Anopheles gambiae and Culex quinquefasciatus from Benin, West Africa. Acta Trop. 2007;101: 207-16.

9. Djouaka $\mathrm{R}$, Irving $\mathrm{H}$, Tukur Z, Wondji CS. Exploring mechanisms of multiple insecticide resistance in a population of the malaria vector Anopheles funestus in Benin. PLoS One. 2011;6:e27760.

10. Djouaka R, Riveron JM, Yessoufou A, Tchigossou G, Akoton R, Irving H, et al. Multiple insecticide resistance in an infected population of the malaria. vector Anopheles funestus in Benin. Parasit Vectors. 2016;9:453.

11. Akogbéto MC, Aïkpon RY, Azondékon R, Padonou GG, Ossè RA, Agossa FR, et al. Six years of experience in entomological surveillance of indoor residual spraying against malaria transmission in Benin: lessons learned, challenges and outlooks. Malar J. 2015;14:242.

12. WHO. Global plan for insecticide resistance management in malaria vectors. Geneva: World Health Organization Press; 2012.

13. Djouaka RJ, Atoyebi SM, Tchigossou G, Riveron JM, Irving H, Akoton R, et al. Evidence of a multiple insecticide resistance in the malaria vector Anopheles funestus in south-west Nigeria. Malar J. 2016;15:565.

14. Okoye PN, Brooke BD, Koekemoer LL, Hunt RH, Coetzee M. Characterisation of DDT, pyrethroid and carbamate resistance in Anopheles funestus from Obuasi, Ghana. Trans R Soc Trop Med Hyg. 2008:102:591-8.

15. Cuamba N, Morgan JC, Irving H, Steven A, Wondji CS. High level of pyrethroid resistance in an Anopheles funestus population of the Chokwe District in Mozambique. PLoS One. 2010;5:e11010.

16. Morgan JC, Irving H, Okedi LM, Steven A, Wondji CS. Pyrethroid resistance in an Anopheles funestus population from Uganda. PLoS One. 2010;5:e11872.

17. Wondji CS, Dabire RK, Tukur Z, Irving H, Djouaka R, Morgan JC. Identification and distribution of a GABA receptor mutation conferring dieldrin resistance in the malaria vector Anopheles funestus in Africa. Insect Biochem Mol Biol. 2011:41:484-91.

18. Kawada H, Dida GO, Ohashi K, Komagata O, Kasai S, Tomita T, et al. Multimodal pyrethroid resistance in malaria vectors, Anopheles gambiae s.S., Anopheles arabiensis, and Anopheles funestus s.s. in western Kenya. PLoS One. 2011;6:48.

19. Samb B, Konate L, Irving H, Riveron JM, Dia I, Faye O, et al. Investigating molecular basis of lambda-cyhalothrin resistance in an Anopheles funestus population from Senegal. Parasit Vectors. 2016:9:449.

20. Irving $\mathrm{H}$, Charles WS. Investigating knockdown resistance (kdr) mechanism against pyrethroids/DDT in the malaria vector Anopheles funestus across Africa. BMC Genet. 2017;18:76.

21. Menze BD, Riveron JM, Ibrahim SS, Irving H, Antonio-Nkondjio C, Awonoambene $\mathrm{PH}$, et al. Multiple insecticide resistance in the malaria vector Anopheles funestus from northern Cameroon is mediated by metabolic resistance alongside potential target site insensitivity mutations. PLoS One. 2016;11:e0163261.

22. Mulamba C, Riveron JM, Ibrahim SS, Irving H, Barnes KG, Mukwaya LG, et al. Widespread pyrethroid and DDT resistance in the major malaria vector Anopheles funestus in east Africa is driven by metabolic resistance mechanisms. PLoS One. 2014;9:e110058.

23. Brooke BD, Hunt R, Koekemoer L, Temu E, Taylor M, Small G, et al. Bioassay and biochemical analyses of insecticide resistance in southern African Anopheles funestus (Diptera: Culicidae). Bull Entomol Res. 2001; 91:265-72. 
24. Riveron JM, Ndula M, Barnes KG, Ibrahim SS, Paine MJI, Wondji CS. Directionally selected cytochrome P450 alleles are driving the spread of pyrethroid resistance in the major malaria vector Anopheles funestus. Proc Natl Acad Sci USA. 2013;110:252-7.

25. Hargreaves K, Koekemoer LL, Brooke BD, Hunt RH, Mthembu J, Coetzee M. Anopheles funestus resistant to pyrethroid insecticides in South Africa. Med Vet Entomol. 2000;14:181-9.

26. Mulamba C, Irving H, Riveron JM, Mukwaya LG, Birungi J, Wondji CS. Contrasting Plasmodium infection rates and insecticide susceptibility profiles between the sympatric sibling species Anopheles parensis and Anopheles funestus s.s.: a potential challenge for malaria vector control in Uganda. Parasit Vectors. 2014;7:71

27. Riveron JM, Yunta C, Ibrahim SS, Djouaka R, Irving H, Menze BD, et al. A single mutation in the GSTe2 gene allows tracking of metabolically based insecticide resistance in a major malaria vector Anopheles funestus. Genome Biol. 2014;15:1-20.

28. Koekemoer LL, Kamau L, Hunt RH, Coetzee M. A cocktail polymerase chain reaction assay to identify members of the Anopheles funestus (Diptera: Culicidae) group. Am J Trop Med Hyg. 2002;66:804-11.

29. Crawford J, Guelbeogo W, Sanou A, Traore A, Vernick K, Sagnon N, Lazzaro S. De novo transcriptome sequencing in Anopheles funestus using Illumina RNA-seq technology. PLoS One. 2010;5:e14202.

30. Gregory R, Darby AC, Irving H, Coulibaly MB, Hughes $M$, Koekemoer LL, et al. A de novo expression profiling of Anopheles funestus, malaria vector in Africa, using 454 pyrosequencing. PLoS One. 2011;6:e17418.

31. Wondji CS, Irving H, Morgan J, Lobo NF, Collins FH, Hunt RH, et al. Two duplicated P450 genes are associated with pyrethroid resistance in Anopheles funestus, a major malaria vector. Genome Res. 2009;19:452-9.

32. Irving H, Riveron J, Ibrahim S, Lobo N, Wondji C. Positional cloning of rp2 QTL associates the P450 genes CYP6Z1, CYP6Z3 and CYP6M7 with pyrethroid resistance in the malaria vector Anopheles funestus. Heredity. 2012;109:383-92.

33. David J-P, Strode C, Vontas J, Nikou D, Vaughan A, Pignatelli PM, et al. The Anopheles gambiae detoxification chip: a highly specific microarray to study metabolic-based insecticide resistance in malaria vectors. Proc Natl Acad Sci USA. 2005;102:4080-4.

34. Hunt RH, Brooke BD, Pillay C, Koekemoer LL, Coetzee M. Laboratory selection for and characteristics of pyrethroid resistance in the malaria vector Anopheles funestus. Med Vet Entomol. 2005;19(3):271-5.

35. Riveron JM, Ibrahim SS, Chanda E, Mzilahowa T, Cuamba N, Irving H, et al. The highly polymorphic CYP6M7 cytochrome P450 gene partners with the directionally selected CYP6P9a and CYP6P96 genes to expand the pyrethroid resistance front in the malaria vector Anopheles funestus in Africa. BMC Genomics. 2014;15:817.

36. Schmittgen D, Livak J. Analyzing real-time PCR data by the comparative $C T$ method. Nat Protoc. 2008:3:1101-8.

37. Thompson JD, Higgins DG, Gibson TJ. CLUSTAL W: Improving the sensitivity of progressive multiple sequence alignment through sequence weighting, position-specific gap penalties and weight matrix choice. Nucleic Acids Res. 1994;22:4673-80.

38. Librado P, Rozas J. DnaSP v5: a software for comprehensive analysis of DNA polymorphism data. Bioinformatics. 2009;25:1451-2.

39. Tamura K, Peterson D, Peterson N, Stecher G, Nei M, Kumar S. MEGA5: Molecular Evolutionary Genetics Analysis using maximum likelihood, evolutionary distance, and maximum parsimony methods. Mol Biol Evol. 2011:28:2731-9.

40. Duangkaew P, Pethuan S, Kaewpa D, Boonsuepsakul S, Sarapusit S, Rongnoparut P. Characterization of mosquito CYP6P7 and CYP6AA3: differences in substrate preference and kinetic properties. Arch Insect Biochem Physiol. 2011;76:236-48.

41. Hemingway J, Hawkes NJ, McCarroll L, Ranson H. The molecular basis of insecticide resistance in mosquitoes. Insect Biochem Mol Biol. 2004;34:653-65.

42. Kostaropoulos I, Papadopoulos Al, Metaxakis A, Boukouvala E, Papadopoulou Mourkidou E. Glutathione S-transferase in the defence against pyrethroids in insects. Insect Biochem Mol Biol. 2001;31:313-9.

43. Vontas JG, Small GJ, Hemingway J. Glutathione S-transferases as antioxidant defence agents confer pyrethroid resistance in Nilaparvata lugens. Biochem J. 2001;357:65-72.

44. Lumjuan N, Rajatileka S, Changsom D, Wicheer J, Leelapat P, Prapanthadara $L A$, et al. The role of the Aedes aegypti Epsilon glutathione transferases in conferring resistance to DDT and pyrethroid insecticides. Insect Biochem Mol Biol. 2011;41:203-9.
45. Strode C, Wondji CS, David JP, Hawkes NJ, Lumjuan N, Nelson DR, et al. Genomic analysis of detoxification genes in the mosquito Aedes aegypti. Insect Biochem Mol Biol. 2008;38:113-23.

46. Wondji CS, Morgan J, Coetzee M, Hunt RH, Steen K, Iv WCB, et al. Mapping a Quantitative Trait Locus ( QTL ) conferring pyrethroid resistance in the African malaria vector Anopheles funestus. BMC Genomics. 2007;8:34.

47. Amenya D, Naguran R, Lo T, Ranson H, Spillings B, Wood O, et al. Over expression of a cytochrome P450 (CYP6P9) in a major African malaria vector, Anopheles funestus, resistant to pyrethroids. Insect Mol Biol. 2008;17:19-25.

48. Akogbeto MC, Djouaka R, Noukpo H. Use of agricultural insecticides in Benin. Bull Soc Pathol Exot. 2005;98:400-5.

49. Yadouleton A, Martin T, Padonou G, Chandre F, Asidi A, Djogbenou L, et al. Cotton pest management practices and the selection of pyrethroid resistance in Anopheles gambiae population in northern Benin. Parasit Vectors. 2011;4:60

50. Djouaka RF, Bakare AA, Bankole HS, Doannio JM, Coulibaly ON, Kossou H, et al. Does the spillage of petroleum products in Anopheles breeding sites have an impact on the pyrethroid resistance? Malar J. 2007;6:159.

51. Elissa N, Mouchet J, Riviere F, Meunier JY, Yao K. Resistance of Anopheles gambiae s.s. to pyrethroids in Côte d'Ivoire. Ann Soc Belg Med Trop. 1993; 73:291-4.

52. Nkya TE, Akhouayri I, Kisinza W, David J-P. Impact of environment on mosquito response to pyrethroid insecticides: facts, evidences and prospects. Insect Biochem Mol Biol. 2013;43:407-16.

53. Jones CM, Toé HK, Sanou A, Namountougou M, Hughes A, Diabaté A, D R, Simard $F$, et al. Additional selection for insecticide resistance in urban malaria vectors: DDT resistance in Anopheles arabiensis from Bobo-Dioulasso, Burkina Faso. PLoS One. 2012;7:e45995.

54. Tang A, Tu C. Biochemical characterization of Drosophila glutathione Stransferases D1 and D21. J Biol Chem. 1994;269:27876-84.

55. Brandt A, Scharf M, Pedra J, Holmes G, Dean A, Kreitman M, et al. Differential expression and induction of two Drosophila cytochrome P450 genes near the Rst(2)DDT locus. Insect Mol Biol. 2002;11:337-41.

56. Barnes KG, Weedall GD, Ndula M, Irving H, Mzihalowa T, Hemingway J, et al. Genomic footprints of selective sweeps from metabolic resistance to pyrethroids in African malaria vectors are driven by scale up of insecticidebased vector control. PLoS Genet. 2017;13:e1006539.

\section{Ready to submit your research? Choose BMC and benefit from:}

- fast, convenient online submission

- thorough peer review by experienced researchers in your field

- rapid publication on acceptance

- support for research data, including large and complex data types

- gold Open Access which fosters wider collaboration and increased citations

- maximum visibility for your research: over $100 \mathrm{M}$ website views per year

At $\mathrm{BMC}$, research is always in progress.

Learn more biomedcentral.com/submissions 